\title{
Activation of the Adipose Tissue NLRP3 Inflammasome Pathway in Cancer Cachexia
}

OPEN ACCESS

Edited by:

Liwu Li,

Virginia Tech, United States

Reviewed by:

Shuobing Chen,

Columbia University Irving Medical

Center, United States

Bhesh Raj Sharma,

St. Jude Children's Research Hospital,

United States

*Correspondence:

Joyce de Cassia Rosa de Jesus

joyrosa@usp.br

Marilia Seelaender

seelaender@usp.br

Specialty section:

This article was submitted to

Molecular Innate Immunity,

a section of the journal

Frontiers in Immunology

Received: 22 June 2021 Accepted: 03 September 2021 Published: 23 September 2021

Citation:

Jesus JCR, Murari ASP, Radloff K,

Moraes RCM, Figuerêdo RG,

Pessoa AFM, Rosa-Neto JC, Matos-Neto EM, Alcântara PSM,

Tokeshi F, Maximiano LF,

Bin FC, Formiga FB, Otoch JP and Seelaender M (2021)

Activation of the Adipose

Tissue NLRP3 Inflammasome

Pathway in Cancer Cachexia.

Front. Immunol. 12:729182.

doi: 10.3389/fimmu.2021.729182
Joyce de Cassia Rosa de Jesus ${ }^{1 *}$, Ariene Soares de Pinho Murari ${ }^{1}$, Katrin Radloff ${ }^{1}$, Ruan Carlos Macêdo de Moraes ${ }^{1}$, Raquel Galvão Figuerêdo ${ }^{1}$, Ana Flavia Marçal Pessoa ${ }^{1}$, José César Rosa-Neto ${ }^{2}$, Emídio Marques Matos-Neto ${ }^{1}$, Paulo S. M. Alcântara ${ }^{3}$, Flavio Tokeshi ${ }^{3}$, Linda Ferreira Maximiano ${ }^{3}$, Fang Chia Bin ${ }^{4}$, Fernanda Bellotti Formiga ${ }^{4}$, José P. Otoch ${ }^{1,3}$ and Marilia Seelaender ${ }^{1 *}$

${ }^{1}$ Cancer Metabolism Research Group, Department of Surgery Laboratório de Investigação Médica (LIM26), Faculdade de Medicina, Universidade de São Paulo, São Paulo, Brazil, ${ }^{2}$ Immunometabolism Laboratory, Institute of Biomedical Sciences, Universidade de São Paulo, São Paulo, Brazil, ${ }^{3}$ University Hospital, Department of Surgical Clinic, Universidade de São Paulo, São Paulo, Brazil, ${ }^{4}$ Department of Coloproctology, Santa Casa de São Paulo, São Paulo, Brazil

Background: Cachexia is a paraneoplastic syndrome that accompanies and compromises cancer treatment, especially in advanced stages, affecting the metabolism and function of several organs. The adipose tissue is the first to respond to the presence of the tumor, contributing to the secretion of factors which drive the systemic inflammation, a hallmark of the syndrome. While inflammation is a defensive innate response, the control mechanisms have been reported to be disrupted in cachexia. On the other hand, little is known about the role of NLRP3 inflammasome in this scenario, a multiprotein complex involved in caspase- 1 activation and the processing of the cytokines $\mathrm{IL}-1 \beta$ and IL-18.

Aim: based on the evidence from our previous study with a rodent model of cachexia, we examined the activation of the NLRP3 inflammasome pathway in two adipose tissue depots obtained from patients with colorectal cancer and compared with that another inflammatory pathway, NF-кB.

Results: For CC we found opposite modulation in ScAT and PtAT for the gene expression

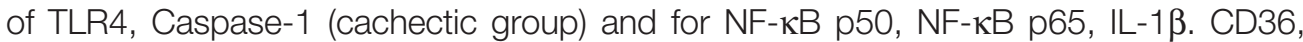
expression was decreased in both depots while that of NLRP3 and IL-18 was higher in both tissues, as compared with controls and weight stable patients (WSC). Caspase-1 basal protein levels in the ScAT culture supernatant were higher in WSC and (weight stable patients) CC, when compared to controls. Basal ScAT explant culture medium $\mathrm{IL}-1 \beta$ and IL-18 protein content in ScAT supernatant was decreased in the WSC and CC as compared to CTL explants.

Conclusions: The results demonstrate heterogeneous responses in the activation of genes of the NLRP3 inflammasome pathway in the adipose tissue of patients with cancer cachexia, rendering this pathway a potential target for therapy aiming at decreasing chronic inflammation in cancer.

Keywords: neoplasms, cachexia, adipose tissue heterogeneity, inflammation, NLRP3 inflammasome 


\section{INTRODUCTION}

Cancer is among the four major causes of premature death in the world. The risk of getting sick and dying from cancer is related to hereditary aspects, increased life expectancy, the process of aging, lifestyle habits, the influence of risk factors, and the environment in which people live in. In low- and middle-income countries, such as Brazil, there has been a reduction in the number of cases of infectious agents-related cancers, such as those in the oral cavity and cervix, and an increase in the types that are more common in developed countries, including colorectal cancer (CRC). The latter is the third most incident type of cancer in the world (1).

Cancer cachexia is an overly debilitating and harmful paraneoplastic syndrome that compromises the therapeutic response and quality of life of patients. Its etiology is complex and not yet fully understood, but sustained systemic inflammation is a peculiar feature, stimulating exacerbated energy expenditure through cytokine secretion by the tumor and host tissues in response to the tumor, causing muscle and adipose tissue loss (2-7).

Considered a multiorgan, white adipose tissue performs an important role in health and disease. It is an active endocrine organ, responsible for the secretion of steroid precursors of hormones, cytokines, autacoids, fatty acids, and derivatives, and the so called adipokines, with functions involved in the regulation of fat storage, energy metabolism, food intake, insulin sensitivity and immunity, amongst many other (8-14). Under the presence of sustained systemic inflammation observed in cancer cachexia, the metabolism and function of the adipose tissue are impaired, in association with morphological and molecular changes (15). Studies have shown that the subcutaneous adipose tissue is the first to be affected in cancer cachexia, but the inflammatory mechanisms that cause adipose mass depletion and increased tissue inflammatory output remain not fully elucidated (15-18).

Adipose tissue acts at the crossroads between metabolism and immunity: as it is an endocrine organ, it is capable of regulating the immune system, and the signaling between these two compartments displays a delicate and intricate balance (2-4, 7). Inflammation is a protective innate response to danger signals and in the presence of cancer cachexia, diverse inflammatory pathways are activated, perhaps in an attempt to restore homeostatic balance (5). Inflammasomes are key regulators of inflammatory processes and are implicated in diseases such as gout and colorectal cancer $(6,8-10)$. NLRP3 inflammasome is a multiprotein complex responsible for the maturation of caspase1 and the processing of cytokines IL- $1 \beta$ and IL-18 (11-14). It is considered the most versatile of this family of intracytoplasmic receptors, owing to its activation by a wide range of factors (15-17).

We have previously shown that there is a distinct pattern of secretion of inflammatory factors by the tumor and the adipose tissue (subcutaneous and peritumoral pads) and differences in the tumor microenvironment in cachectic patients versus weight-stable patients $(18,19)$. In a previous study we showed, for the first time, that the inflammasome pathway may be involved in adipose tissue inflammation in a rodent model of cancer cachexia (20).
Due to the contribution of adipose tissue to several biological processes and to cancer cachexia, we sought to investigate the activation of components of the NLRP3 inflammasome pathway in the two white adipose tissue depots in patients with colorectal cancer. A PubMed search retrieves only 5 articles under "inflammasome and cachexia". As demonstrated for obesity, different adipose compartments present heterogeneous function/contribution in health and disease. The present study was designed as to confirm that the changes reported previously for animal model of cachexia (20), with induction of the inflammasome pathway, are also present in the human form of the disease.

\section{METHODS}

\section{Patients, Ethics and Cachexia Diagnosis}

This research project was approved, following the Declaration of Helsinki, by the Research Ethics Committees of the "Faculdade de Medicina" (CAAE no. 54503716.1.0000.0065), of the University Hospital (CAAE no. 54503716.1.3001.0076) and the Institute of Biomedical Sciences (CAAE no. 54503716.1.3002.5467) of the University of São Paulo (USP). Twenty-eight volunteers were recruited into the study at diagnosis. Informed consent before to surgery was obtained from all participants. Inclusion criteria were diagnosis of colorectal cancer with an indication for surgery, or with a surgical indication for correction of abdominal wall hernias (umbilical and inguinal), cholecystectomies, and abdominal proctoplexy, and willingness to participate in the study. Exclusion criteria: having received antibiotic therapy, antiinflammatory therapy, or anti-cancer treatment. extreme low weight or obesity (BMI $<18$ and $>30 \mathrm{~kg} / \mathrm{m}^{2}$, respectively), chronic heart failure, liver or kidney failure, chronic obstructive pulmonary disease, acquired immunodeficiency syndrome (AIDS), inflammatory bowel disease (IBD), hepatitis and autoimmune diseases.

For the diagnosis of cachexia, the criteria established in international consensus by Evans and others were employed (21): unintentional weight loss in the last 12 months or less or body mass index less than $20 \mathrm{~kg} / \mathrm{m}^{2}$; decreased muscle strength; fatigue; anorexia; altered biochemical parameters (C-Reactive Protein (CRP) $>5 \mathrm{mg} / \mathrm{l}$; Hemoglobin $<12 \mathrm{~g} / \mathrm{dl}$; albumin $<3.5 \mathrm{~g} / \mathrm{dl}$ ). Subjects were distributed into 3 groups: control patients (CTL, $\mathrm{n}=8$ ), weight-stable colorectal cancer patients (WSC, $\mathrm{n}=10$ ), and cachectic colorectal cancer patients $(C C, n=10)$.

\section{Obtention of Biopsies}

During the surgical procedure, fragments of approximately $1 \mathrm{~g}$ of subcutaneous adipose tissue (ScAT) and visceral adipose tissue (mesenteric) immediately close to the tumor (peritumoral adipose tissue, PtAT) were collected.

\section{Explant Incubation}

Adipose tissue explants were distributed in 12-well culture plates, with approximately $500 \mathrm{mg}$ per well and incubated in DMEM containing $10 \%$ fetal bovine serum (FBS), supplemented or not 
with lipopolysaccharide (LPS, from Escherichia coli serotype O55:B55, SIGMA ${ }^{\circledR}$, product number L2880) $(1 \mu \mathrm{g} / \mathrm{ml})$, in a humidified atmosphere of $10 \% \mathrm{CO} 2$ at $37^{\circ} \mathrm{C}$ for $24 \mathrm{~h}(22,23)$. The unstimulated well received $500 \mu \mathrm{L}$ DMEM, and the stimulated well received $490 \mu \mathrm{l}$ DMEM and $10 \mu \mathrm{l}$ LPS. After 24 hours, the culture medium was collected for protein quantification of IL- $1 \beta$, IL-18, and caspase-1, and the explants were frozen at $-80^{\circ} \mathrm{C}$ for further RNA extraction.

\section{RT-PCR}

Total RNA of subcutaneous and peritumoral adipose tissue was extracted with Trizol $^{\odot}$ reagent (Invitrogen, Carlsbad, CA) observing the manufacturer's instructions. The concentration of total RNA was evaluated with the spectrophotometer. The cDNA was obtained by reverse transcription (RT) using $1 \mu \mathrm{g}$ of total RNA from each sample per reaction, in a final volume of $20 \mu$ l. The target gene was normalized to the reference gene GAPDH. The mRNA levels were determined using the $2^{-\Delta \Delta C t}$ method, in which, for each sample, the $\Delta \mathrm{Ct}$ value was obtained by subtracting the control gene values from those of the target gene; then, the average $\Delta \mathrm{Ct}$ value of the control group was subtracted from the sample to get a $-\Delta \Delta$ Ct value (24). The primers used are listed in Table 1.

\section{Protein Expression Assessment}

The protein concentration of the culture medium supernatant was determined by the Bradford method (Bradford Protein Assay, BioRad Laboratories). Afterward, the quantification of proteins (caspase-1, IL-1 $\beta$, and IL-18) was performed using ELISA. The kits used for these tests were Human Caspase-1 SimpleStep ELISA $^{\circledR}$ Kit (Abcam, Cat. No. ab219633), ELISA Max ${ }^{\text {TM }}$ Deluxe Set Human IL-1 $\beta$ (Biolegend ${ }^{\circledR}$, Cat. No. 437004), and RayBio ${ }^{\circledR}$ Human IL-18 ELISA Kit (RayBiotech, Cat. No. ELH-IL18).

\section{Statistical Analysis}

Comparisons among groups were carried out using the ANOVA 1-way test, for data with normal distribution, or the KruskalWallis test, for data with asymmetric distribution. To assess the dispersion of nominal variables, the Chi-square test $\left(X^{2}\right)$ was used. For multiple comparisons, the ANOVA 2-way test was used. The Uncorrected Fisher's LSD post-test was applied. Outliers were identified using the Rout method and removed from the analysis.

For all analyses, a significance level of $\mathrm{p}<0.05$ was adopted, using the Prism ${ }^{\circledR}$ version 8.0 statistical software (GraphPad Software, Inc.). Data were expressed as mean \pm standard error unless otherwise indicated.

\section{RESULTS}

\section{Clinical Characteristics of Patients}

Table 2 shows the clinical characteristics of the patients. Age, sex, and BMI were similar among groups. Height was lower in the CC versus CTL. Weight loss was greater in the CC. The comorbidities reported at the time of recruitment by the volunteers were allergy, dyslipidemia, hypertension, asthma, hypothyroidism, hypercholesterolemia, depression, epilepsy, type 2 diabetes, pre-diabetes, and pain.
TABLE 1 | List of primers used.

\begin{tabular}{|c|c|}
\hline Gene (specie) & Sequence $5^{\prime} \rightarrow 3^{\prime}$ \\
\hline TLR4, mRNA & Forward primer: TाT ATC CAG GTG TGA AAT CCA G \\
\hline $\begin{array}{l}\text { NM_138554.4 Homo } \\
\text { sapiens }\end{array}$ & Reverse primer: AGA TGC TAG ATT TGT CTC CAC AG \\
\hline CD36, mRNA & Forward primer: GGA AGA ACA AAT CTA TAC ACA \\
\hline NM_000072.3 Homo & GGG \\
\hline sapiens & $\begin{array}{l}\text { Reverse primer: GAT TAA TGG TAC AGA TGC AGC } \\
\text { CT }\end{array}$ \\
\hline$N F-\kappa B$ p50, mRNA & Forward primer: ACA CTT AGC AAT CAT CCA CC \\
\hline $\begin{array}{l}\text { NM_003998.3 Homo } \\
\text { sapiens }\end{array}$ & Reverse primer: AAT CCT CCA CCA CAT CTT CC \\
\hline NF-kB p65, mRNA & Forward primer: ATA CCA CCA AGA CCC ACC C \\
\hline $\begin{array}{l}\text { NM_021975.3 Homo } \\
\text { sapiens }\end{array}$ & Reverse primer: GCC TCA TAG AAG CCA TCC \\
\hline NLRP3, mRNA & Forward primer: CAT TGA GAA CTG TCA TCG GG \\
\hline $\begin{array}{l}\text { NM_004895.4 Homo } \\
\text { sapiens }\end{array}$ & Reverse primer: GCT GTT CAC CAA TCC ATG AG \\
\hline Caspase-1, mRNA & Forward primer: TGC TTC GGA CAT GAC TAC AG \\
\hline $\begin{array}{l}\text { NM_033292.3 Homo } \\
\text { sapiens }\end{array}$ & Reverse primer: GTT TCT TCC CAC AAA TGC CT \\
\hline IL-1 $1 \beta$, mRNA & Forward primer: ACA GAT GAA GTG CTC CTT CC \\
\hline $\begin{array}{l}\text { NM_000576.2 Homo } \\
\text { sapiens }\end{array}$ & Reverse primer: ATC TTC CTC AGC TTG TCC A \\
\hline IL-18, mRNA & Forward primer: CCT GGA ATC AGA TTA CTT TGG C \\
\hline $\begin{array}{l}\text { NM_001562.3 Homo } \\
\text { sapiens }\end{array}$ & Reverse primer: GGG TGC ATT ATC TCT ACA GTC \\
\hline GAPDH, mRNA & Forward primer: CCT CTG ACT TCA ACA GCG AC \\
\hline $\begin{array}{l}\text { NM_002046.6 Homo } \\
\text { sapiens }\end{array}$ & Reverse primer: CGT TGT CAT ACC AGG AAA TGA G \\
\hline
\end{tabular}

TLR4, Toll-like receptor 4; CD36, Cluster of Differentiation 36; NF- $k B$ p50, Nuclear Factor kB, p50 subunit, NF- kB p65; Nuclear Factor kB, p65 subunit; NLRP3, NLR, Family pyrin domain containing 3; IL-1 $\beta$, Interleukin-1 beta; IL-18, Interleukin-18; GAPDH, Glyceraldehyde-3-phosphate dehydrogenase.

We grouped the colorectal tumors according to location, in the right colon (cecum, ascending, hepatic flexure, and proximal $2 / 3$ of the transverse colon) and left colon ( $1 / 3$ distal of the transverse colon, flexure splenic, descending, sigmoid, rectosigmoid, and rectum). As for the anatomical location of the tumor, most patients presented cancer in the left colon, both for WSC group (80\%) and CC (60\%). Regarding tumor staging, the percentages were higher in stages II and III, in both groups with cancer.

There was no difference between the mean age or sex among the groups. Height was lower in the CC group, and the two cancer groups were equal in terms of BMI. BMI calculation is not an adequate tool to assess body composition, but it has been used as a cachexia marker (25). Analyzing several meta-analyses, the CUP Panel (Continuous Update Project, World Cancer Research Fund) indicated that individuals with BMI $>27 \mathrm{~kg} / \mathrm{m}^{2}$ are at a higher risk of developing CRC (26). About $80 \%$ of cancer patients experience involuntary weight loss, a cardinal clinical criterion in the diagnosis of cachexia. In this study, the usual weight of CC was equal to that of CTL at the time of recruitment. The average weight loss percentage of WSC was 5.1\%, and in the CC group it was $11.6 \%$, in 12 months or less.

Three patients in WSC group and nine in CC group reported having comorbidities; 2 from the WSC group and 3 from the CC group reported having more than one comorbidity. The most frequent comorbidity was systemic arterial hypertension. 
TABLE 2 | General and clinical characteristics.

\begin{tabular}{|c|c|c|c|c|}
\hline & CTL & WSC & CC & $\mathbf{p}$ \\
\hline n & 8 & 10 & 10 & \\
\hline Women (n) (\%) & $3(38 \%)$ & $6(60 \%)$ & $9(90 \%)$ & 0.065 \\
\hline Men (n) (\%) & $5(62 \%)$ & $4(40 \%)$ & $1(10 \%)$ & \\
\hline Age (years) & $49.5 \pm 5.7$ & $57 \pm 3.2$ & $64.5 \pm 5.8$ & 0.13 \\
\hline Height (m) & $1.69 \pm 0.03$ & $1.60 \pm 0.02^{a}$ & $1,59 \pm 0.03^{b}$ & $0.02^{\star}$ \\
\hline Previous weight $(\mathrm{kg})$ & $68.8 \pm 4.8$ & $65.6 \pm 4.6$ & $68.3 \pm 3.6$ & 0.85 \\
\hline Current weight (kg) & $68.5 \pm 4.7$ & $61.6 \pm 4.0$ & $60 \pm 2.5$ & 0.27 \\
\hline Weight loss (\%) & $0[0 ; 0,9]$ & $4.1[0 ; 9.2]$ & $10.5[7.9 ; 17.1]^{b}$ & $0.01^{*}$ \\
\hline BMI (kg/m²) & $23.8 \pm 1.3$ & $23.7 \pm 1.2$ & $23.8 \pm 0.8$ & 0.99 \\
\hline \multicolumn{5}{|l|}{ Tumor site } \\
\hline Right colon (n) (\%) & N. A. & $2(20 \%)$ & $4(40 \%)$ & 0.62 \\
\hline Left colon (n) (\%) & N. A. & 8 (80\%) & $6(60 \%)$ & \\
\hline \multicolumn{5}{|l|}{ Tumor staging (TNM) } \\
\hline I & N. A. & 1 & 1 & 0.8 \\
\hline II & N. A. & 5 & 3 & \\
\hline III & N. A. & 3 & 4 & \\
\hline IV & N. A. & 1 & 2 & \\
\hline \multicolumn{5}{|l|}{ Comorbidities } \\
\hline Allergy & 1 & N. A. & N. A. & NA \\
\hline Dyslipidemia & N. A. & 2 & N. A. & \\
\hline Hypertension & N. A. & 2 & 4 & \\
\hline Asthma & N. A. & N. A. & 1 & \\
\hline Hypothyroidism & N. A. & N. A. & 2 & \\
\hline Hypercholesterolemia & N. A. & N. A. & 1 & \\
\hline Depression & N. A. & 1 & 1 & \\
\hline Epilepsy & N. A. & 1 & N. A. & \\
\hline Type 2 Diabetes & N. A. & N. A. & 1 & \\
\hline Pre-diabetes & N. A. & N. A. & 1 & \\
\hline Pain & N. A. & N. A. & 1 & \\
\hline
\end{tabular}

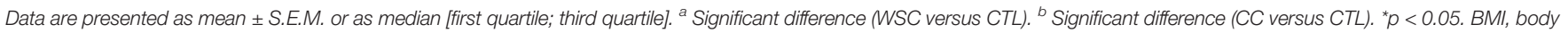
mass index; TNM, tumor-node-metastasis (Classification of Malignant Tumors). N.A., not applied.

Colorectal cancer usually presents in a greater proportion in elderly patients, who also tend to have more chronic diseases.

Dysregulated lipid metabolism is also a hallmark of cancer, as it has the crucial function of providing constituents for the cell membrane and tumorigenic pathways (27). The levels of total cholesterol and the LDL fraction were higher in WSC when compared to CTL; these differences were not observed when comparing CC to the control (non-cancer) group. The post-test analysis showed the levels of total cholesterol and LDL fraction to be lower in CC when compared to WSC. The HDL fraction, serum triglycerides and glucose did not vary among the groups. For the diagnosis of cachexia, we used serum hemoglobin, CRP, and albumin (21). Serum hemoglobin levels were lower in the CC compared to the
CTL, indicating anemia in cachectic patients. CRP levels were higher in CC in relation to the CTL, showing systemic inflammation in CC group. Albumin showed no difference among groups (Table 3).

\section{Analysis of Gene and Protein Expression}

Two important receptors in the adipose tissue that are relevant for inflammasome activation are TLR4 and CD36. The analysis of the unstimulated gene expression of TLR4 showed no distinct differences among the study groups in subcutaneous or peritumoral adipose tissue explants. Incubation with LPS induced TLR4 in ScAT explants in CTL and CC, but in the latter, significance was not reached. Basal CD36 gene expression did not differ among the explants obtained from the 3 groups in

TABLE 3 | Biochemical parameters.

\begin{tabular}{|c|c|c|c|c|}
\hline & CTL & wsc & $\mathrm{CC}$ & p \\
\hline Total cholesterol (mg/dL) & $201.6 \pm 13.0$ & $246.9 \pm 17.6^{a}$ & $165.2 \pm 5.7^{b}$ & $0.0005^{\star \star \star}$ \\
\hline HDL cholesterol (mg/dL) & $51.9 \pm 4.5$ & $53.2 \pm 4.2$ & $46.5 \pm 5.9$ & 0.5 \\
\hline Triglycerides (mg/dL) & $115.9 \pm 25.2$ & $116.1 \pm 17$ & $113.6 \pm 11.5$ & 0.9 \\
\hline Glucose (mg/dL) & $98.9 \pm 2.3$ & $98.6 \pm 7.5$ & $100.4 \pm 3.9$ & 0.9 \\
\hline Hemoglobin (g/dL) & $14.2 \pm 0.8$ & $13.3 \pm 0.5$ & $10.7 \pm 0.6^{b}$ & 0.001 \\
\hline
\end{tabular}

Data are expressed as mean \pm S.E.M. ${ }^{a}$ Significant difference (WSC versus CTL). ${ }^{b}$ Significant difference $(C C$ versus $W S C) .{ }^{*} p<0.05,{ }^{* * *} p<0.005$. 
either of the adipose tissue depots. In subcutaneous explants from WSC, CD36 expression increased in response to LPS, as well as in the peritumoral tissue from CC (Figure 1).

The activation of the TLR4, as well as the CD36 receptor cascade, result in the release of the NF- $\kappa B$ p50/p65 complex from $\mathrm{I} \kappa \mathrm{B}$ and its translocation into the nucleus, where the transcription of NLRP3 is induced. The gene expression analysis of the NF- $\mathrm{\kappa B}$ subunits p50 and p65 revealed that the mean p50 expression in subcutaneous CC explants was about 2 -fold higher than in CTL or WSC. LPS stimulus suppressed p50 expression in CC subcutaneous explants, while in the peritumoral adipose tissue an opposite effect of LPS led to an increase in p50 expression in CC. No differences in basal NF- $\kappa B$ p65 gene expression was observed among the groups for any of the studied adipose depots. In contrast to p50, p65 gene expression increased in response to incubation with LPS in CC subcutaneous explants. The same effect of LPS on p65 was observed in peritumoral adipose tissue explants from CC group. The unstimulated mean NLRP3 gene expression in ScAT explants was about 5-fold higher than in CTL or WSC. This was also the case for PtAT. LPS displayed a suppressive effect on NLRP3 expression in CC in both studied adipose tissue depots. With a decrease of approximately $60 \%$, this effect was stronger in ScAT than in PtAT, where NLRP3 expression was reduced by a third (Figure 2 ).
The inflammasome activates caspase-1, which in turn, activates the cytokines IL-1 $\beta$ and IL-18 by cleaving the propeptide. In the subcutaneous adipose tissue explants, basal caspase-1 gene expression was not different among the groups. However, caspase-1 protein levels in the explant culture medium were significantly higher in ScAT of WSC and CC, as compared to CTL. LPS increased caspase- 1 gene expression in CC ScAT explants, but this LPS effect was not observed when assessing the protein concentrations in the explant incubation supernatant. Although there was no difference in Caspase-1 gene expression between WSC and CC in ScAT, basal caspase-1 expression in PtAT of CC patients was higher than in the tissue from WSC. Unlike the ScAT of CC, the peritumoral adipose tissue of CC was not sensitive to the LPS stimulus. Basal IL-1 $\beta$ gene expression was lower in both cancer groups when compared to CTL, with a significant difference in WSC and a trend for CC. In peritumoral adipose tissue there was also a trend for a lower IL-1b expression in CC compared to WSC. However, the basal IL- $1 \beta$ protein content in ScAT explant supernatant was not significantly different among the groups. Incubation with LPS suppressed IL-1 $\beta$ gene expression in ScAT of CTL and CC, while there was no LPS-induced effect on IL- $1 \beta$ gene expression in PtAT. The downregulating effect of LPS on IL- $1 \beta$ in ScAT CTL explants was also confirmed by the lower protein levels found in the supernatant. Interestingly, in the supernatants obtained from
A

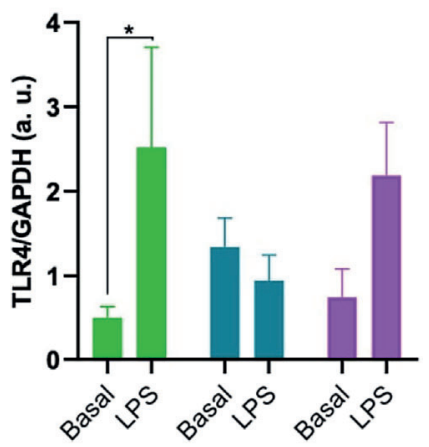

C

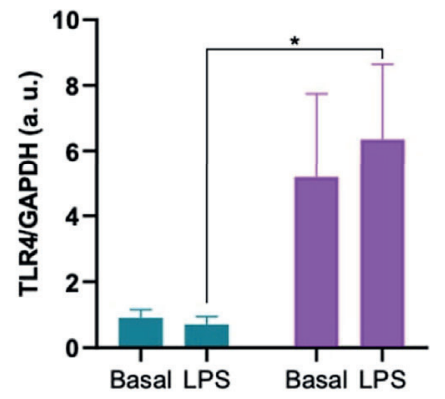

B

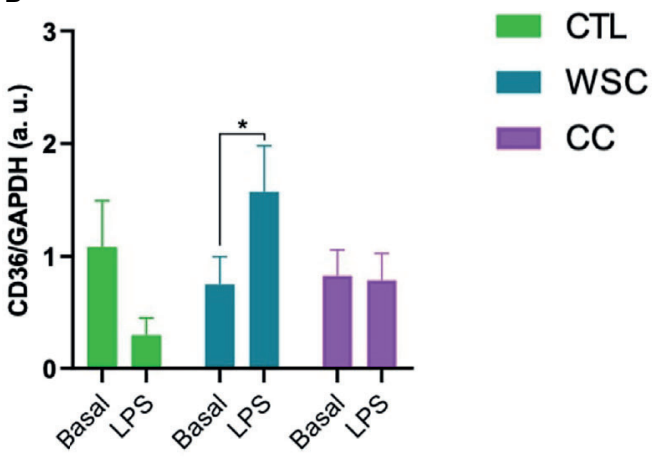

D

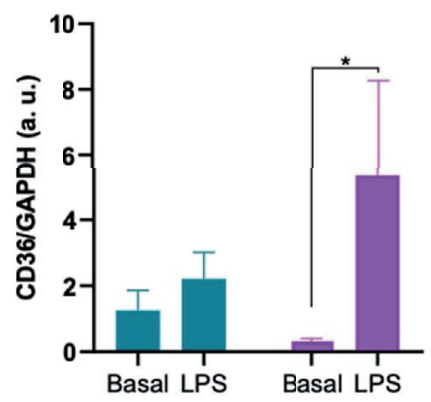

FIGURE 1 | Gene expression of receptors involved in inflammasome activation. (A, B) TLR4 and CD36 gene expression in ScAT and (C, D) TLR4 and CD36 gene expression in PtAT. TLR4, Toll-like receptor 4; CD36, Cluster of Differentiation 36; GAPDH, Glyceraldehyde-3-phosphate dehydrogenase a.u.; arbitrary units; LPS, lipopolysaccharide. ${ }^{*} \mathrm{p}<0.05$. 

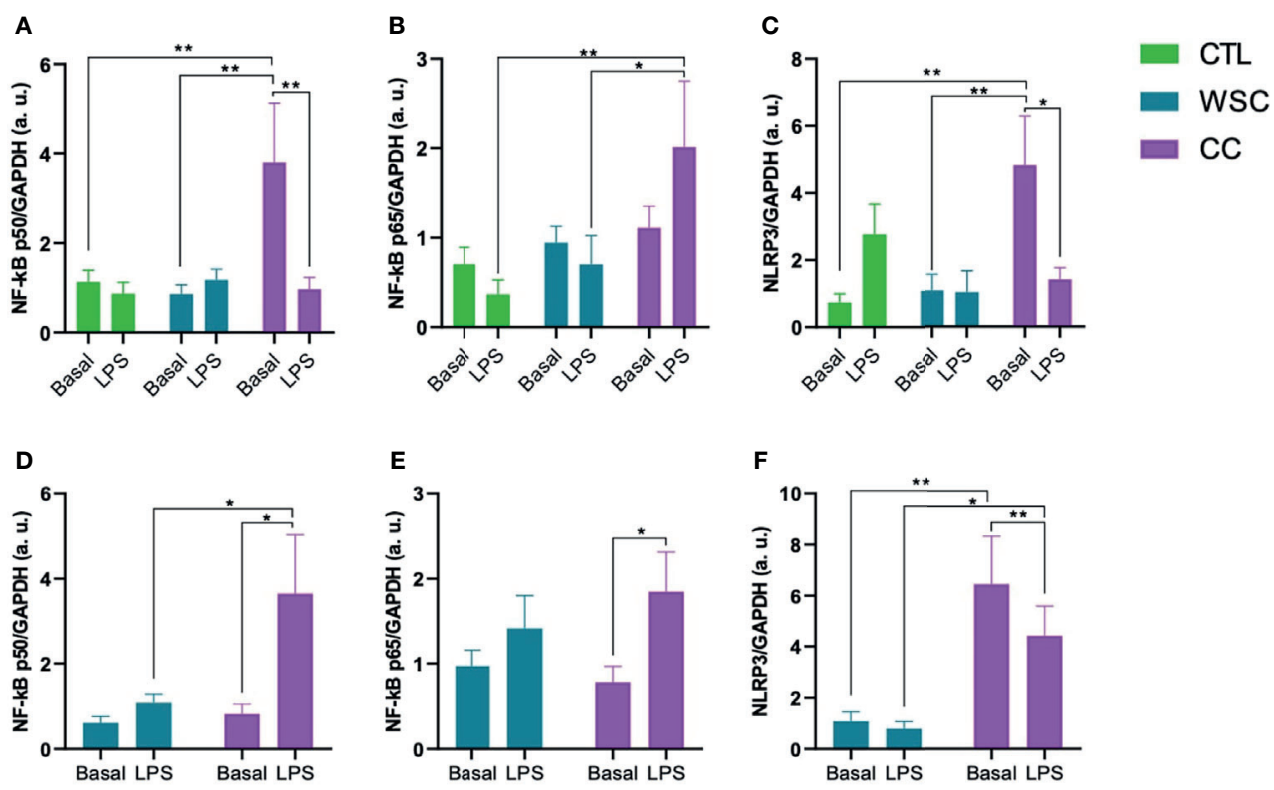

FIGURE 2 | NLRP3 induction via NF-kB Pathway. (A-C) NF-кB p50/p65 and NLRP3 gene expression in ScAT and (D-F) NF-kB p50/p65 and NLRP3 gene expression in PtAT. NF-кB p50: Nuclear Factor kB, p50 subunit; NF-kB p65: Nuclear Factor kB, p65 subunit; NLRP3, NLR, Family pyrin domain containing 3; GAPDH, Glyceraldehyde-3-phosphate dehydrogenase; a.u., arbitrary units; LPS, lipopolysaccharide. ${ }^{\star} p<0.05$ and ${ }^{* *} p<0.01$.

CC explants, the LPS incubation caused an increase in IL-1b protein content, which was contrary to the gene expression data. Basal IL-18 gene and protein expression did not differ among the groups for ScAT explants, whereas in PtAT tissue IL-18 gene expression tended to be higher in CC when compared to WSC. In ScAT explants, incubation with LPS resulted in an increase of IL-18 gene expression in WSC which was not reflected by the supernatant protein data in this group, while in CC, the challenge led to a significant increase in IL-18 protein content. No effect of LPS was observed in the peritumoral depot (Figure 3).

\section{DISCUSSION}

\section{Clinical Findings}

An increase in the number of cases of CRC has been observed in patients under the age of 50 years, mainly in the left colon. There are embryological, biological, anatomical, and molecular differences in CRC located on the right and left sides (28), being considered as different biological entities (29). Tumors located in the right colon are associated with anemia, advanced staging, and advanced age; the lesions tend to be polypoid and bulky and grow into the lumen of the organ, while the characteristics of left-sided tumors are infiltrating and constrictive lesions causing obstruction $(29,30)$. One study demonstrated that patients with left-sided CRC had longer disease-free survival than those with right-sided, depending on the stage of the tumor. They also showed that, among patients who lost weight, the highest percentage was among patients with CRC on the right side (31). In our study, most tumors were concentrated in the left side of the colon $(80 \%$ in WSC and 60\% in CC). Lim and coll. reported that patients with tumors on the right side of the colon presented increased tumor size, advanced cancer, and lower disease-free and overall survival rates (30). Our work shows the highest percentages at stages II and III. Even if they have the same type of cancer and tumor burden, one patient may develop cachexia and another may not; Fearon and others attributed this fact to possible genotypic variations in immunity $(32)$. We $(18,19)$ have previously shown that there is also a distinct pattern of secretion of inflammatory factors by the tumor and differences in the tumor microenvironment in cachectic patients versus weight-stable patients.

Cancer cachexia is a syndrome that is difficult to diagnose and treat; its etiology remains partly unknown, and its pathophysiology is complex and poorly understood, despite the efforts of decades of study. It is difficult to disentangle its roots from cancer and it is common to have it confused with other conditions, such that, in most cases, cachexia is only diagnosed when there is no longer a turning point in the patient's response, that is, refractory cachexia. Therapeutic strategies currently used for cancer cachexia include exercise, nutritional support and surgical removal of the tumor (especially of obstructive malignancy) (33). Clinical trials employ protocols of monodrug or a combination of drugs and nutrients (34-36). However, so far, no therapy has been described to comprehensively ameliorate cachexia.

Cachexia not only impacts cancer progression but also compromises the therapeutic response, increases treatment costs and length of hospitalization (37), and is the immediate cause of death in at least $20 \%$ of patients $(33,38)$. In a systematic review, Anker and others estimated that, of patients diagnosed with colorectal cancer, $50 \%$ are at risk of developing cachexia and 

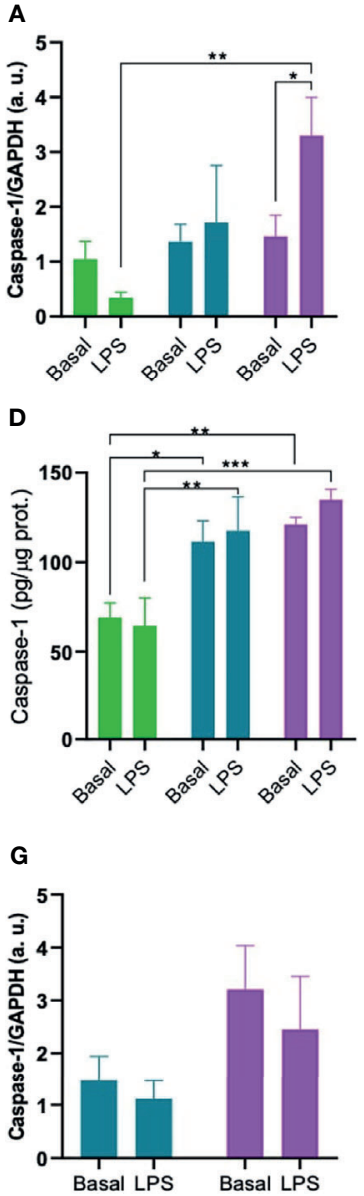
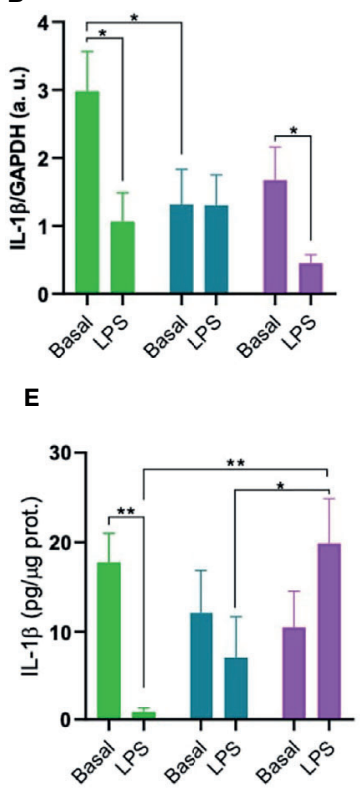

H

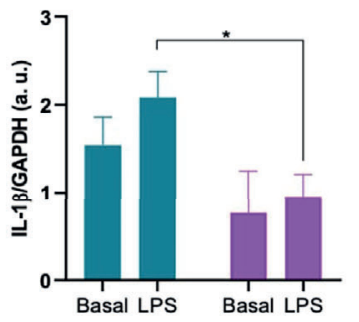

C

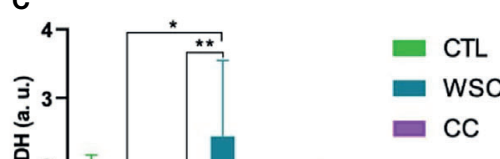

CC

FIGURE 3 | Inflammasomal cytokine activation mediated by caspase-1. Gene expression (A-C) and protein levels (D-F) of caspase-1, IL-1 3 and IL-18 in ScAT and (G-I) genes expression of caspase-1, IL-1 $\beta$ and IL-18 in PtAT. IL-1 $\beta$, Interleukin-1 beta; IL-18, Interleukin-18; GAPDH, Glyceraldehyde-3-phosphate dehydrogenase; a.u., arbitrary units; LPS, lipopolysaccharide. ${ }^{\star} \mathrm{p}<0.05 ;{ }^{\star \star} \mathrm{p}<0.01$ and ${ }^{\star \star \star} \mathrm{p}<0.005$.

calculated the 5-year survival rate for patients with both pathologies at $66 \%$ (39).

The aim of the study was to confirm in human cachexia what we have previously shown in animal models of the disease: white adipose tissue plays a relevant role for sustained systemic inflammation. In these earlier studies we have reported that adipose tissue response in cachexia was not uniform in terms of tissue architectural changes, nor did different anatomical depots contribute to the same extent to inflammation $(7,19,20,40-48)$. Furthermore, while the NF- $\kappa \mathrm{B}$ pathway has been accredited much importance in cachexia, the inflammasome pathway contribution remains unclear. Thus, we compared the activation of both intracellular pathways in human tissue, as to investigate whether there could be differences in comparison to models (with which most molecular studies are carried out).

When assessing whether there was heterogeneity in the inflammatory response of adipose tissue depending on the anatomical location (mesenteric, retroperitoneal, and epididymal) in an animal model of cachexia, Neves and others (20) reported a marked heterogeneous response having demonstrated that the inflammasome pathway was involved in time-dependent adipose tissue inflammation in cachectic animal adipose tissue, and that adipocytes obtained from different depots presented heterogeneity in the response.

ScAT and VAT (corresponding to PtAT, in the present study scenario) are very distinct, so differences in gene and protein expression profiles may contribute to the observed disturbances. Different fat depots differ in cell size, physiological function, and contribution to disease states (49). In VAT, adipocytes have greater lipolytic activity and generally secrete more proinflammatory cytokines than ScAT, contributing to systemic inflammation associated with metabolic disorders. In ScAT, the storage of triacylglycerols occurs over the long term, while lipolysis is lower, being this a more, more densely vascularized, and metabolically less active than VAT. Finally, this tissue shows lower density of secretion of pro-inflammatory factors in humans (50).

Zoico and colleagues described in vitro PtAT morphofunctional changes, for example, shrinkage in size and number of adipocytes with intense lipolysis and a higher rate of macrophage infiltration (51); 
the same was seen in subcutaneous adipose tissue of cachectic patients (47). To address the importance of different intracellular pathways in the two adipose depots we studied under basal or stimulated conditions, explants of subcutaneous and visceral white adipose tissue.

LPS was added to the incubation medium of explants as a stimulus to induce the entire NLRP3 inflammasome signaling cascade. Yet, by addressing the unstimulated expression in the subcutaneous and peritumoral tissues, reflecting the actual condition of patients at the time of surgery, we already managed to identify differences. It has been shown that adipose tissue expresses all TLR subtypes, which is associated with NF- $\kappa \mathrm{B}$ activation and subsequent release of cytokines (52, 53). TLR4 mRNA showed a different basal expression pattern in ScAT and PtAT explants. While in ScAT, unstimulated TLR4 gene expression was not altered between the study groups (Figure 1), in PtAT, TLR4 gene expression was higher in CC than in WSC explants. Interestingly, both adipose tissue depots also differed in their sensitivity towards LPS. In the ScAT explants of CTL and CC TLR4 expression was upregulated by LPS, while in CC explants derived from the PtAT depot LPS incubation failed to induce TLR4. It is possible that CC PtAT TLR4 expression reached already a status of saturation. On the other hand, as the expression was found to be already high, one may suggest that no further increase, as induced by LPS could be achieved. This might be also a possibility for explants of the WSC group, since neither ScAT, nor PtAT explants showed further TLR4 induction by LPS. In the literature, it was shown, that the GTPase Rab7, which is currently gaining importance as an oncosuppressor (54), impairs TLR4 by promoting its lysosomal degradation (54) and may therefore play a role in immune-suppressive mechanisms during cancer progression and cachexia development.

CD36 is not directly part of the NLRP3 inflammasome pathway but is an important signaling molecule interacting with TLR4 (55). CD36 (also known as fatty acid translocase) is an integral membrane glycoprotein expressed in most cells, particularly those involved in glucose homeostasis, such as adipocytes and skeletal muscle cells, facilitating the uptake of long-chain fatty acids and anionic or oxidized lipoproteins (56, 57). CD36 gene signaling has been implicated in the development of chronic diseases (55) and genetic variants have been associated with lipid abnormalities and susceptibility to metabolic syndrome in humans (58). Although in both adipose tissue depots CD36 gene expression was not altered in the studied groups, it was induced by LPS only in WSC ScAT explants and CC PtAT explants. This is in contrast to the results of TLR4 in CC PtAT explants and could point to shifts between different inflammasome activation routes due to tissuespecific changes during cancer cachexia progression.

The activation of TLR4 or CD36 results in the activation of NF$\kappa \mathrm{B}$, which is a family of five transcriptional factor subunits, that are activated canonically (which acts on inflammation) and noncanonical (which regulates various immune functions), responding to different types of receptors and their ligands. Control the expression of several genes involved in inflammation, immunity, cell survival, proliferation, and differentiation (59-65).
The gene expression of the two NF- $\mathrm{BB}$ domains was not significantly different (Figure 2) in the adipose tissue of the patients. However, the activity of NF- $\kappa B$ depends on posttranslational modifications such as the cleavage of the I $\mathrm{I} B$, and previous analysis of our group already showed changes in $\mathrm{NF}-\kappa \mathrm{B}$ complex proteins in adipose tissue in cancer cachexia (62). In both ScAT and PtAT CC explants, p65 was upregulated by LPS. NF- $\kappa B$ p50 followed that pattern in CC PtAT explants but in CC ScAT explants LPS had a contrary effect on p50 and lead to downregulation.

The expression of NLRP3 was increased in the cachectic group in both tissues of patients in the CC group. Experimental animal studies have linked NLRP3 inflammasome activation to inflammatory bowel diseases $(15,16)$. In IL-10 gene knock-out animals, the absence of this molecule led to uninterrupted activation of the inflammasome, due to the constant stimulation of microorganisms, causing chronic colitis (16). Knock-out animals for the nlrp3 gene exhibited greater weight loss (66). Studies on single nucleotide polymorphisms in the nlrp3 gene demonstrate susceptibility to Crohn's disease, a risk factor for CRC (67), suggesting that a defective innate immune response impairs the removal of antigens and pathogens, leading to disease development (68). High level of NLRP3 expression correlated with advanced tumors, occurrence of metastases, vascular and lymph node invasion in patients with CRC (69). Deficiency in the genes nlrp3 and caspase- 1 is related with a strong inflammatory response and destruction of the epithelial barrier, with consequent dysplasia, tumorigenesis, and greater tumor burden in the colon $(70,71)$. Caspase-1 gene knock-outs show weight loss greater than $20 \%$ of initial weight, drastic colonic shortening, and more severe signs of epithelial injury than control animals, indicating that caspase- 1 is necessary for tissue regeneration and repair after damage (72). Although basal Caspase-1 gene expression showed no alterations among the groups for ScAT, the protein levels in the explant culture supernatant were higher in WSC and CC when compared to the CTL group. It remains unclear whether the active form of Caspase- 1 is also increased, as we did not evaluate this parameter. In PtAT Caspase-1 gene expression tended to be higher in CC than in WSC explants.

Gene expression for the cytokine IL- $1 \beta$ in the CC was increased in ScAT and decreased in PtAT, as previously demonstrated by our group by Riccardi et al (73). Through the action of the inflammasome, Caspase- 1 is activated resulting in the cleavage and activation of IL-1 $\beta$ and IL-18. High concentration of IL-1 $\beta$ and IL-18 cytokines is observed in patients with Crohn's disease (74). The unregulated expression of IL- $1 \beta$ has been associated with inflammation of the intestinal mucosa in patients with IBD, in vitro and in animal models, as it can promote the epithelial-mesenchymal transition in intestinal cells $(15,75)$, with loss of expression of ecadherin, thus contributing to the invasion, growth, and metastasis (75). Stage II patients who presented polymorphisms for the IL-1 $\beta$ gene had a higher risk of CRC recurrence (76). Basal ScAT explant culture IL-1 $\beta$ protein content and mRNA expression appeared to be lower in WSC and CC (Figure 3). The experimental design does not allow a conclusion about the activation of IL-1 $\beta$. However, the increase in IL-1 $1 \beta$ protein content after LPS incubation points to a 
higher capacity for cytokine production in ScAT in CC under immune challenging conditions. Therefore, we postulate that besides involvement in tumor progression, this cytokine, deriving from the ScAT contributes to cachexia in patients.

IL-18 is constitutively expressed in some tissues, such as the intestine, where it contributes to the integrity of the intestinal barrier and the maintenance of a healthy microbiota (77). Gene and circulating expression of IL-18 increase in gastrointestinal cancers, with dual activity in CRC: in early stages, it promotes tissue repair protection, by down-regulating the IL-22 binding protein (IL-22BP); IL-22BP controls the biological activity of IL-22, which protects intestinal cells from damage during inflammation; and later, IL-18 acts by stimulating tumor growth and cell invasion $(15,78)$. IL-18 protein levels in ScAT supernatant were also decreased in the WSC and CC group and showed a similar sensitivity to LPS though with lower fold change. In PtAT IL- $1 \beta$ and IL-18 mRNA showed an opposite expression pattern as IL-1 $\beta$ mRNA expression was higher in WSC than in CC and Il-18 lower in WSC than in CC. Protein analysis in PtAT would help to draw a more distinct picture of adipose tissue depot-specific production of inflammasomal targets.

The present results confirm the importance of the adipose tissue as a contributor to inflammation in human cachexia, showing that the regulation of both NF- $\kappa \mathrm{B}$ and inflammasome pathway are depot-specific, paving avenues for targeted treatment.

This study had several limitations. The volunteers' previous body weight was reported by the patient and, therefore, inaccuracies are possible. It was not possible to perform the analysis of the patients' body composition using DEXA because there was not enough time between recruitment and surgery. The number of individuals in each group was low due to the difficulty of obtaining surgical paired samples of subcutaneous and peritumoral adipose tissue. Due to the intrinsic variation between samples of human tissue, some analyzes were not performed for all individuals initially enrolled, as some samples showed aberrant values. It was also not possible to assess the protein profile in the PtAT, with biopsies being of small dimensions. Since the primary intent of our project was to evaluate ScAT inflammasome in human cachexia, we prioritized this analysis. As far as we know, this is the first study to show that the NLRP3 pathway is also activated in human cachexia (similarly to the previously demonstrated in rodents).

\section{REFERENCES}

1. BRASIL. Ministério Da Saúde. Instituto Nacional do Câncer José Alencar Gomes Da Silva (INCA). In: Estimativa 2020 - Incidência De Câncer No Brasil. Rio de Janeiro: INCA (2019).

2. Federico A, D'Aiuto E, Borriello F, Barra G, Gravina AG, Romano M, et al. Fat: A Matter of Disturbance for the Immune System. World J Gastroenterol (2010) 16(38):4762-72. doi: 10.3748/wjg.v16.i38.4762

3. Grant RW, Dixit VD. Adipose Tissue as an Immunological Organ. Obesity (2015) 23(3):512-8. doi: 10.1002/oby.21003

4. Deng T, Lyon CJ, Bergin S, Caligiuri MA, Hsueh WA. Obesity, Inflammation, and Cancer. Annu Rev Pathol Mech Dis (2016) 11:421-49. doi: 10.1146/ annurev-pathol-012615-044359

5. Khatami M. Unresolved Inflammation: "Immune Tsunami" or Erosion of Integrity in Immune-Privileged and Immune-Responsive Tissues and Acute

\section{DATA AVAILABILITY STATEMENT}

The original contributions presented in the study are included in the article/supplementary material. Further inquiries can be directed to the corresponding authors.

\section{ETHICS STATEMENT}

The studies involving human participants were reviewed and approved by Faculdade de Medicina, Hospital Universitário and Instituto de Ciências Biomédicas - University of São Paulo. The patients/participants provided their written informed consent to participate in this study.

\section{AUTHOR CONTRIBUTIONS}

JJ, JO, and MS conceived the project. JJ performed the experiments, with the help of AM, KR, RM, RF, and AP. JJ wrote the manuscript. JO and MS ensured funding, supervised the project, and helped to correct the manuscript. JR-N and EM$\mathrm{N}$ provided technical support. PA, FT, LM, FB, and FF provided the adipose tissue samples. All authors have contributed equally to this work. All authors contributed to the article and approved the submitted version.

\section{FUNDING}

We thank CAPES (Coordenação de Aperfeiçoamento de Pessoal de Nível Superior) for the scholarship. Financial support was provided by FAPESP 12/50079-0 and 20/7765-6.

\section{ACKNOWLEDGMENTS}

The Authors thank Emilia Ribeiro and Ivanir Pires for excellent technical assistance.

and Chronic Inflammatory Diseases or Cancer. Expert Opin Biol Ther (2011) 11(11):1419-32. doi: 10.1517/14712598.2011.592826

6. Menu P, Vince JE. The NLRP3 Inflammasome in Health and Disease: The Good, the Bad and the Ugly. Clin Exp Immunol (2011) 166(1):1-15. doi: 10.1111/j.1365-2249.2011.04440.x

7. Seelaender MCL, Batista ML. Adipose Tissue Inflammation and Cancer Cachexia: The Role of Steroid Hormones. Horm Mol Biol Clin Investig (2014) 17(1):5-12. doi: 10.1515/hmbci-2013-0040

8. Kolb R, Liu GH, Janowski AM, Sutterwala FS, Zhang W. Inflammasomes in Cancer: A Double-Edged Sword. Protein Cell (2014) 5(1):12-20. doi: 10.1007/s13238-013-0001-4

9. Paramel GV, Sirsjö A, Fransén K. Role of Genetic Alterations in the NLRP3 and CARD8 Genes in Health and Disease. Mediators Inflamm (2015) 2015:110. doi: $10.1155 / 2015 / 846782$

10. Sharma BR, Kanneganti TD. NLRP3 Inflammasome in Cancer and Metabolic Diseases. Nat Immunol (2021) 22(5):550-9. doi: 10.1038/s41590-021-00886-5 
11. Broz P, Dixit VM. Inflammasomes: Mechanism of Assembly, Regulation and Signalling. Nat Rev Immunol (2016) 16(7):407-20. doi: 10.1038/nri.2016.58

12. Choi JSA, Ryter SW, Krishnan SM, Sobey CG, Latz E, Mansell A, et al. The Role of Macrophage-Derived IL-1 in Induction and Maintenance of Angiogenesis. J Leukoc Biol (2014) 7(6):193-203. doi: 10.14348/ mollcells.2014.0104

13. Martinon F, Burns K, Tschopp J. The Inflammasome: A Molecular Platform Triggering Activation of Inflammatory Caspases and Processing of Pro-IL-1b. Mol Cell (2002) 10:417-26. doi: 10.1016/S1097-2765(02)00599-3

14. Chamaillard M, Girardin SE, Viala J, Philpott DJ. Nods, Nalps and Naip: Intracellular Regulators of Bacterial-Induced Inflammation. Cell Microbiol (2003) 5(9):581-92. doi: 10.1046/j.1462-5822.2003.00304.x

15. Ahechu P, Zozaya G, Martí P, Hernández-Lizoáin JL, Baixauli J, Unamuno X, et al. NLRP3 Inflammasome: A Possible Link Between Obesity-Associated Low-Grade Chronic Inflammation and Colorectal Cancer Development. Front Immunol (2018) 9(December):2918. doi: 10.3389/fimmu.2018.02918

16. Zhang J, Fu S, Sun S, Li Z, Guo B. Inflammasome Activation has an Important Role in the Development of Spontaneous Colitis. Mucosal Immunol (2014) 7 (5):1139-50. doi: 10.1038/mi.2014.1

17. Schroder K, Tschopp J. The Inflammasomes. Cell (2010) 140(6):821-32. doi: 10.1016/j.cell.2010.01.040

18. Matos-Neto EM, Lima JDCC, de Pereira WO, Figuerêdo RG, Riccardi DM do $\mathrm{R}$, Radloff K, et al. Systemic Inflammation in Cachexia - Is Tumor Cytokine Expression Profile the Culprit? Front Immunol (2015) 6:1-11. doi: 10.3389/ fimmu.2015.00629

19. Neto NIP, Murari AS de P, Oyama LM, Otoch JP, Alcântara PSM, Tokeshi F, et al. Peritumoural Adipose Tissue Pro-Inflammatory Cytokines Are Associated With Tumoural Growth Factors in Cancer Cachexia Patients. J Cachexia Sarcopenia Muscle (2018) 9(6):1101-8. doi: 10.1002/jcsm.12345

20. Neves RX, Rosa-Neto JC, Yamashita AS, Matos-Neto EM, Riccardi DMR, Lira FS, et al. White Adipose Tissue Cells and the Progression of Cachexia: Inflammatory Pathways. J Cachexia Sarcopenia Muscle (2016) 7(2):193-203. doi: $10.1002 / j c s m .12041$

21. Evans WJ, Morley JE, Argilés J, Bales C, Baracos V, Guttridge D, et al. Cachexia: A New Definition. Clin Nutr (2008) 27(6):793-9. doi: 10.1016/ j.clnu.2008.06.013

22. Vatier C, Kadiri S, Muscat A, Chapron C, Capeau J, Antoine B. Visceral and Subcutaneous Adipose Tissue From Lean Women Respond Differently to Lipopolysaccharide-Induced Alteration of Inflammation and Glyceroneogenesis. Nutr Diabetes (2012) 2(DECEMBER):e51-7. doi: 10.1038/nutd.2012.29

23. Szalowska E, Dijkstra M, Elferink MG, Weening D, De Vries M, Bruinenberg M, et al. Comparative Analysis of the Human Hepatic and Adipose Tissue Transcriptomes During LPS-Induced Inflammation Leads to the Identification of Differential Biological Pathways and Candidate Biomarkers. BMC Med Genomics (2011) 4:71. doi: 10.1186/1755-8794-4-71

24. Livak KJ, Schmittgen TD. Analysis of Relative Gene Expression Data Using Real-Time Quantitative PCR and the 2- $\Delta \Delta$ CT Method. Methods (2001) 25 (4):402-8. doi: 10.1006/meth.2001.1262

25. Dev R. Measuring Cachexia-Diagnostic Criteria. Ann Palliat Med (2019) 8 (2):24-32. doi: 10.21037/apm.2018.08.07

26. World Cancer Research Fund/American Institute of Cancer Research. Diet, Nutrition, Physical Activity and Colorectal Cancer. Contin Updat Proj [Internet]. World Cancer Research Fund/American Institute of Cancer Research (2018).

27. Al-Zhoughbi W, Huang J, Paramasivan GS, Till H, Pichler M, Guertl-Lackner B, et al. Tumor Macroenvironment and Metabolism. Semin Oncol (2014) 41 (2):281-95. doi: 10.1053/j.seminoncol.2014.02.005

28. Dekker E, Tanis PJ, Vleugels JLA, Kasi PM, Wallace MB. Colorectal Cancer. Lancet (2019) 394(10207):1467-80. doi: 10.1016/S0140-6736(19)32319-0

29. Patel M, McSorley ST, Park JH, Roxburgh CSD, Edwards J, Horgan PG, et al. The Relationship Between Right-Sided Tumour Location, Tumour Microenvironment, Systemic Inflammation, Adjuvant Therapy and Survival in Patients Undergoing Surgery for Colon and Rectal Cancer. Br J Cancer (2018) 118(5):705-12. doi: 10.1038/bjc.2017.441

30. Lim DR, Kuk JK, Kim T, Shin EJ. Comparison of Oncological Outcomes of Right-Sided Colon Cancer Versus Left-Sided Colon Cancer After Curative Resection. Med (United States) (2017) 96(42):1-7. doi: 10.1097/ MD.0000000000008241
31. Qin Q, Yang L, Sun Y-K, Ying J-M, Song Y, Zhang W, et al. Comparison of 627 Patients With Right- and Left-Sided Colon Cancer in China: Differences in Clinicopathology, Recurrence, and Survival. Chronic Dis Transl Med (2017) 3(1):51-9. doi: 10.1016/j.cdtm.2017.02.004

32. Fearon KCH, Glass DJ, Guttridge DC. Cancer Cachexia: Mediators, Signaling, and Metabolic Pathways. Cell Metab (2012) 16(2):153-66. doi: 10.1016/ j.cmet.2012.06.011

33. Vaitkus JA, Celi FS. The Role of Adipose Tissue in Cancer-Associated Cachexia. Exp Biol Med (2017) 242(5):473-81. doi: 10.1177/1535370216683282

34. Baracos VE, Martin L, Korc M, Guttridge DC, Fearon KCH. Cancer-Associated Cachexia. Nat Rev Dis Prim (2018) 4:17105. doi: 10.1038/nrdp.2017.105

35. Anderson LJ, Albrecht ED, Garcia JM. Update on Management of CancerRelated Cachexia. Curr Oncol Rep (2017) 19(1):1-11. doi: 10.1007/s11912017-0562-0

36. Aoyagi T, Terracina KP, Raza A, Matsubara H, Takabe K. Cancer Cachexia, Mechanism and Treatment. World J Gastrointest Oncol (2015) 7(4):17. doi: 10.4251/wjgo.v7.i4.17

37. Karin M, Bogut A, Hojsak I, Babić E, Volarić M, Bevanda M. Nutritional Status and Its Effect on Complications in Patients With Colorectal Cancer. Wien Klin Wochenschr (2020) 132(15-16):431-7. doi: 10.1007/s00508-020-01671-4

38. Bing C, Trayhurn P. New Insights Into Adipose Tissue Atrophy in Cancer Cachexia. Proc Nutr Soc (2009) 68(4):385-92. doi: 10.1017/S0029665109990267

39. Anker MS, Holcomb R, Muscaritoli M, von Haehling S, Haverkamp W, Jatoi A, et al. Orphan Disease Status of Cancer Cachexia in the USA and in the European Union: A Systematic Review. J Cachexia Sarcopenia Muscle (2019) 10(1):22-34. doi: 10.1002/jcsm.12402

40. Lira FS, Rosa JC, Zanchi NE, Yamashita AS, Lopes RD, Lopes AC, et al. Regulation of Inflammation in the Adipose Tissue in Cancer Cachexia: Effect of Exercise. Cell Biochem Funct (2009) 27(2):71-5. doi: 10.1002/cbf.1540

41. Henriques FS, Sertié RAL, Franco FO, Knobl P, Neves RX, Andreotti S, et al. Early Suppression of Adipocyte Lipid Turnover Induces Immunometabolic Modulation in Cancer Cachexia Syndrome. FASEB J (2017) 31(5):1976-86. doi: 10.1096/fj.201601151R

42. Batista ML, Peres SB, McDonald ME, Alcantara PSM, Olivan M, Otoch JP, et al. Adipose Tissue Inflammation and Cancer Cachexia: Possible Role of Nuclear Transcription Factors. Cytokine (2012) 57(1):9-16. doi: 10.1016/ j.cyto.2011.10.008

43. Alves MJ, Figuerêdo RG, Azevedo FF, Cavallaro DA, Neto NIP, Lima JDC, et al. Adipose Tissue Fibrosis in Human Cancer Cachexia: The Role of Tgf $\beta$ Pathway. BMC Cancer (2017) 17(1):190. doi: 10.1186/s12885-017-3178-8

44. Batista ML, Henriques FS, Neves RX, Olivan MR, Matos-Neto EM, Alcântara PSM, et al. Cachexia-Associated Adipose Tissue Morphological Rearrangement in Gastrointestinal Cancer Patients. J Cachexia Sarcopenia Muscle (2016) 7(1):37-47. doi: 10.1002/jcsm.12037

45. Batista ML Jr, Neves RX, Peres SB, Yamashita AS, Shida CS, Farmer SR, et al. Heterogeneous Time-Dependent Response of Adipose Tissue During the Development of Cancer Cachexia. J Endocrinol (2012) 215(3):363-73. doi: 10.1530/JOE-12-0307

46. Bertevello PS, Seelaender MCL. Heterogeneous Response of Adipose Tissue to Cancer Cachexia. Braz J Med Biol Res (2001) 34(9):1161-7. doi: 10.1590/ S0100-879X2001000900009

47. Silvério R, Lira FS, Oyama LM, Oller Do Nascimento CM, Otoch JP, Alcântara PSM, et al. Lipases and Lipid Droplet-Associated Protein Expression in Subcutaneous White Adipose Tissue of Cachectic Patients With Cancer. Lipids Health Dis (2017) 16(1):1-11. doi: 10.1186/s12944-017-0547-x

48. Yamashita AS, das Neves RX, Rosa-Neto JC, Lira F dos S, Batista ML, Alcantara PS, et al. White Adipose Tissue IFN- $\gamma$ Expression and Signalling Along the Progression of Rodent Cancer Cachexia. Cytokine (2017) 89:122-6. doi: 10.1016/j.cyto.2016.02.015

49. Santosa S, Swain J, Tchkonia T, Kirkland JL, Jensen MD. Inflammatory Characteristics of Adipose Tissue Collected by Surgical Excision vs Needle Aspiration. Int J Obes (2015) 39(5):874-6. doi: 10.1038/ijo.2014.185

50. Wronska A, Kmiec Z. Structural and Biochemical Characteristics of Various White Adipose Tissue Depots. Acta Physiol (2012) 205(2):194-208. doi: 10.1111/j.1748-1716.2012.02409.x

51. Zoico E, Rizzatti V, Darra E, Budui SL, Franceschetti G, Vinante F, et al. Morphological and Functional Changes in the Peritumoral Adipose Tissue of Colorectal Cancer Patients. Obesity (2017) 25:S87-94. doi: 10.1002/oby.22008 
52. Schäffler A, Schölmerich J. Innate Immunity and Adipose Tissue Biology. Trends Immunol (2010) 31(6):228-35. doi: 10.1016/j.it.2010.03.001

53. Kopp A, Buechler C, Neumeier M, Weigert J, Aslanidis C, Schölmerich J, et al. Innate Immunity and Adipocyte Function: Ligand-Specific Activation of Multiple Toll-Like Receptors Modulates Cytokine, Adipokine, and Chemokine Secretion in Adipocytes. Obesity (2009) 17(4):648-56. doi: 10.1038/oby.2008.607

54. Guerra F, Bucci C. Role of the RAB7 Protein in Tumor Progression and Cisplatin Chemoresistance. Cancers (Basel) (2019) 11(8):1096. doi: 10.3390/ cancers 11081096

55. Sheedy FJ, Grebe A, Rayner KJ, Kalantari P, Ramkhelawon B, Carpenter SB, et al. CD36 Coordinates NLRP3 Inflammasome Activation by Facilitating Intracellular Nucleation of Soluble Ligands Into Particulate Ligands in Sterile Inflammation. Nat Immunol (2013) 14(8):812-20. doi: 10.1038/ni.2639

56. Heni M, Müssig K, MacHicao F, MacHann J, Schick F, Claussen CD, et al. Variants in the CD36 Gene Locus Determine Whole-Body Adiposity, But Have No Independent Effect on Insulin Sensitivity. Obesity (2011) 19 (5):1004-9. doi: 10.1038/oby.2010.251

57. Wang J, Li Y. CD36 Tango in Cancer: Signaling Pathways and Functions. Theranostics (2019) 9(17):4893-908. doi: 10.7150/thno.36037

58. Pietka TA, Schappe T, Conte C, Fabbrini E, Patterson BW, Klein S, et al. Adipose and Muscle Tissue Profile of CD36 Transcripts in Obese Subjects Highlights the Role of CD36 in Fatty Acid Homeostasis and Insulin Resistance. Diabetes Care (2014) 37(7):1990-7. doi: 10.2337/dc13-2835

59. Cildir G, Low KC, Tergaonkar V. Noncanonical NF-kb Signaling in Health and Disease. Trends Mol Med (2016) 22(5):414-29. doi: 10.1016/j.molmed.2016.03.002

60. Hoesel B, Schmid JA. The Complexity of NF- kb Signaling in Inflammation and Cancer. Mol Cancer (2013) 12(1):86. doi: 10.1186/1476-4598-12-86

61. Giuliani C, Bucci I, Napolitano G. The Role of the Transcription Factor Nuclear Factor-Kappa B in Thyroid Autoimmunity and Cancer. Front Endocrinol (Lausanne) (2018) 9(AUG):1-8. doi: 10.3389/fendo.2018.00471

62. Camargo RG, dos Reis Riccardi DM, Ribeiro HQT, Carnevali LC, de MatosNeto EM, Enjiu L, et al. Nf-kbp65 and Expression of Its Pro-Inflammatory Target Genes Are Upregulated in the Subcutaneous Adipose Tissue of Cachectic Cancer Patients. Nutrients (2015) 7(6):4465-79. doi: 10.3390/ nu7064465

63. Karin M. Nuclear Factor- $\mathrm{kb}$ in Cancer Development and Progression How Infection and Inflammation Affect Cancer Development. Nature (2006) 441:431-6. doi: 10.1038/nature04870

64. Rakoff-Nahoum S, Medzhitov R. Toll-Like Receptors and Cancer. Nat Rev Cancer (2009) 9(1):57-63. doi: 10.1038/nrc2541

65. Lin L, Wu C, Hu K. Tissue Plasminogen Activator Activates NF- kb Through a Pathway Involving Annexin A2 CD11b and Integrin-Linked Kinase.Pdf. J Am Soc Nephrol (2012) 23:1329-38. doi: 10.1681/ASN.2011111123

66. Hirota SA, Ng J, Lueng A, Khajah M, Parhar K, Li Y, et al. NLRP3 Inflammasome Plays a Key Role in the Regulation of Intestinal Homeostasis. Inflammation Bowel Dis (2011) 17(6):1359-72. doi: 10.1002/ibd.21478

67. Karki R, Kanneganti TD. Diverging Inflammasome Signals in Tumorigenesis and Potential Targeting. Nat Rev Cancer (2019) 19(4):197-214. doi: 10.1038/ s41568-019-0123-y

68. Villani AC, Lemire M, Fortin G, Louis E, Silverberg MS, Collette C, et al. Common Variants in the NLRP3 Region Contribute to Crohn's Disease Susceptibility. Nat Genet (2009) 41(1):71-6. doi: 10.1038/ng.285
69. Wang B, Li H, Wang X, Zhu X. The Association of Aberrant Expression of NLRP3 and P-S6K1 in Colorectal Cancer. Pathol Res Pract (2020) 216 (1):152737. doi: 10.1016/j.prp.2019.152737

70. Zaki MH, Vogel P, Body-Malapel M, Lamkanfi M, Kanneganti T-D. IL-18 Production Downstream of the Nlrp3 Inflammasome Confers Protection Against Colorectal Tumor Formation. J Immunol (2010) 185(8):4912-20. doi: 10.4049/jimmunol.1002046

71. Zaki MH, Boyd KL, Vogel P, Kastan MB, Lamkanfi M, Kanneganti TD. The NLRP3 Inflammasome Protects Against Loss of Epithelial Integrity and Mortality During Experimental Colitis. Immunity (2010) 32(3):379-91. doi: 10.1016/j.immuni.2010.03.003

72. Dupaul-Chicoine J, Yeretssian G, Doiron K, Bergstrom KSB, McIntire CR, LeBlanc PM, et al. Control of Intestinal Homeostasis, Colitis, and ColitisAssociated Colorectal Cancer by the Inflammatory Caspases. Immunity (2010) 32(3):367-78. doi: 10.1016/j.immuni.2010.02.012

73. Riccardi DM. Perfil Lipídico E Inflamação Sistêmica Na Caquexia Associada Ao Câncer Dissertertation (Master's Degree). São Paulo: Universidade de São Paulo Instituto de Ciências Biomédicas. Departamento de Biologia Celular e do Desenvolvimento (2015).

74. Becker C, Watson AJ, Neurath MF. Complex Roles of Caspases in the Pathogenesis of Inflammatory Bowel Disease. Gastroenterology (2013) 144 (2):283-93. doi: 10.1053/j.gastro.2012.11.035

75. Li Y, Wang L, Pappan L, Galliher-Beckley A, Shi J. IL-1 $\beta$ Promotes Stemness and Invasiveness of Colon Cancer Cells Through Zeb1 Activation. Mol Cancer (2012) 11:1-13. doi: 10.1186/1476-4598-11-87

76. Lurje G, Hendifar AE, Schultheis AM, Pohl A, Husain H, Yang D, et al. Polymorphisms in Interleukin 1 Beta and Interleukin 1 Receptor Antagonist Associated With Tumor Recurrence in Stage II Colon Cancer. Pharmacogenet Genomics (2009) 19(2):95-102. doi: 10.1097/FPC.0b013e32831a9ad1

77. Rathinam VAK, Chan FKM. Inflammasome, Inflammation, and Tissue Homeostasis. Trends Mol Med (2018) 24(3):304-18. doi: 10.1016/ j.molmed.2018.01.004

78. Karki R, Man SM, Kanneganti TD. Inflammasomes and Cancer. Physiol Behav (2017) 5(2):94-9. doi: 10.1158/2326-6066.CIR-16-0269

Conflict of Interest: The authors declare that the research was conducted in the absence of any commercial or financial relationships that could be construed as a potential conflict of interest.

Publisher's Note: All claims expressed in this article are solely those of the authors and do not necessarily represent those of their affiliated organizations, or those of the publisher, the editors and the reviewers. Any product that may be evaluated in this article, or claim that may be made by its manufacturer, is not guaranteed or endorsed by the publisher.

Copyright (c) 2021 Jesus, Murari, Radloff, Moraes, Figuerêdo, Pessoa, Rosa-Neto, Matos-Neto, Alcântara, Tokeshi, Maximiano, Bin, Formiga, Otoch and Seelaender. This is an open-access article distributed under the terms of the Creative Commons Attribution License (CC BY). The use, distribution or reproduction in other forums is permitted, provided the original author(s) and the copyright owner(s) are credited and that the original publication in this journal is cited, in accordance with accepted academic practice. No use, distribution or reproduction is permitted which does not comply with these terms. 